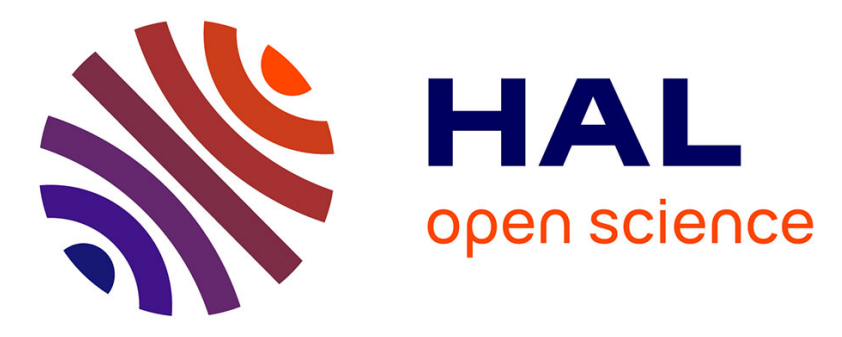

\title{
Long-term quality of life after breast cancer: a French registry-based controlled study
}

Delphine Klein, Mariette Mercier, Edwige Abeilard, Marc Puyraveau, Arlette

Danzon, Véronique Dalstein, Astrid Pozet, Anne-Valérie Guizard, Michel Henry-Amar, Michel Velten

\section{To cite this version:}

Delphine Klein, Mariette Mercier, Edwige Abeilard, Marc Puyraveau, Arlette Danzon, et al.. Longterm quality of life after breast cancer: a French registry-based controlled study. Breast Cancer Research and Treatment, 2011, 129 (1), pp.125-134. 10.1007/s10549-011-1408-3 . hal-00616292

\section{HAL Id: hal-00616292 \\ https://hal.science/hal-00616292}

Submitted on 22 Aug 2011

HAL is a multi-disciplinary open access archive for the deposit and dissemination of scientific research documents, whether they are published or not. The documents may come from teaching and research institutions in France or abroad, or from public or private research centers.
L'archive ouverte pluridisciplinaire HAL, est destinée au dépôt et à la diffusion de documents scientifiques de niveau recherche, publiés ou non, émanant des établissements d'enseignement et de recherche français ou étrangers, des laboratoires publics ou privés. 
Long-term quality of life after breast cancer: a French registry-based controlled study

Delphine Klein ${ }^{1}$, Mariette Mercier ${ }^{2,4}$, Edwige Abeilard ${ }^{3}$, Marc Puyraveau ${ }^{4}$, Arlette Danzon ${ }^{5}$, Véronique Dalstein $^{2}$, Astrid Pozet ${ }^{2,4}$, Anne-Valérie Guizard ${ }^{3}$, Michel Henry-Amar ${ }^{3}$ and Michel Velten ${ }^{1,6}$

1 Department of Epidemiology and Public Health, Bas-Rhin Cancer Registry, EA 3430, University of Strasbourg, Strasbourg, France

${ }^{2}$ Department of Biostatistics, UPRES EA 3181, University of Franche-Comté, Besançon, France

${ }^{3}$ Calvados Cancer Registry, François Baclesse Comprehensive Cancer Center, Caen, France

${ }^{4}$ Cancer Clinical Research Unit, University Hospital Jean Minjoz, Besançon, France

${ }^{5}$ Doubs Cancer Registry, University Hospital Jean Minjoz, Besançon, France

${ }^{6}$ Paul Strauss Comprehensive Cancer Center, Strasbourg, France

Corresponding author:

Michel Velten

Department of Epidemiology and Public Health, Faculty of Medicine, 4 rue Kirschleger, 67085 Strasbourg, France,

and Paul Strauss Comprehensive Cancer Center, Strasbourg, France

Tel: +33368 853191

Fax: +33 368853189

E-mail: michel.velten@unistra.fr 


\begin{abstract}
Population-based studies on quality of life (QOL) of long-term breast cancer survivors are quite recent and insufficient attention has been paid to the effect of time since diagnosis. We compared long-term QOL of population-based breast cancer survivors 5, 10 and 15 years after diagnosis with that of healthy controls. Breast cancer survivors were randomly selected from three population-based cancer registries (Bas-Rhin, Calvados and Doubs, France) along with healthy controls, stratified for age and place of residence, randomly selected from electoral rolls. Participants completed five self-administered questionnaires: the European Organization for Research and Treatment of Cancer Quality of Life Questionnaire Core 30 (EORTC QLQ-C30), Short Form-36 (SF-36), Spielberger State-Trait Anxiety Inventory (STAI), Multidimensional Fatigue Inventory (MFI) and a life conditions questionnaire. A four-level categorical variable and analysis of variance were used to compare QOL scores of breast cancer survivors by period $(5,10$ or 15 years) of diagnosis with those of controls, adjusted for sociodemographic data and comorbidities. Six hundred and fifty-two cases and 1,188 controls participated in the study. For many QOL scales, scores were significantly different between cancer survivors and controls. A clinically significant difference was evidenced for the fatigue scales, the SF36 physical functioning, rolephysical and role-emotional scales, with more favorable results for controls. Differences decreased with time and 15-year cancer survivors were generally not different from controls. Scores were particularly influenced by age and mean household income. More efforts should be made, specifically during the first five to ten years after diagnosis, to help women with breast cancer to overcome their impairment in QOL.
\end{abstract}

Keywords: breast cancer, long-term survivors, population-based study, quality of life, time since diagnosis 


\section{Introduction}

As for most industrialized countries, breast cancer is an important public health issue in France. It is currently the first cancer affecting women and its incidence has doubled during the last twenty-five years (from 22,000 new cases in 1980 to 50,000 cases in 2005) [1]. Young women pay an increasing tribute to this disease: sixty percent of women developing breast cancer are less than 65 years old [2]. Improvements in cancer treatments, early diagnosis and screening have led to an increased number of long-term breast cancer survivors. Whereas measurement and analysis of quality of life (QOL) in breast cancer patients included in clinical trials has become customary, long-term population-based comparative evaluation of QOL is quite recent [3-9]. In population-based studies where long-term effects of cancer on QOL were analyzed, the effect of time since diagnosis was almost never accounted for. Moreover, few studies have been performed on a large scale with a sufficient number of participants - none of them in France.

Therefore, we decided to perform a multicenter population-based study on patients randomly selected from the French regional cancer registries of Bas-Rhin, Calvados and Doubs to compare QOL of breast cancer survivors 5, 10 and 15 years after diagnosis with QOL of healthy controls.

\section{Materials and methods}

\section{Study design}

We conducted a cross-sectional descriptive survey of long-term breast cancer survivors (named "cases" hereafter). These cases were randomly selected from files of the three population-based cancer registries of BasRhin (North-Eastern France), Calvados (North-Western France) and Doubs (Eastern France). These registries cover a total population of 2.2 million inhabitants [2], representing $3.6 \%$ of the French population. In these three areas, the distribution of women by age group was comparable with the age distribution of women in France. Cases were eligible if they had only developed breast cancer, and were able to provide a signed informed consent. On the basis of the information provided by the referent physician and by the respondents in the questionnaires, cases who received cancer therapy during the last five years - hormonotherapy excepted - were not eligible to participate.

In order to study the effect of time since diagnosis on QOL, cases were selected among patients diagnosed in 1990,1995 or 2000.

Cancer survivors were compared with controls randomly selected from electoral rolls of the three areas covered by the registries, with stratification on age ( \pm 10 years) and place of residence (urban, $\geq 2000$ inhabitants vs. 
rural area, < 2000 inhabitants) according to the INSEE (National Institute for Statistics and Economic Studies) definition at the time of the survey. Controls were checked against the registry database to ensure they had no prior history of cancer with the exception of non invasive skin cancer. Two controls were selected per case.

\section{Instruments}

Participants completed a questionnaire that included sociodemographic characteristics and a number of standardized validated instruments translated in French language designed to assess QOL, anxiety and fatigue. General QOL was assessed using two questionnaires: the European Organization for Research and Treatment of Cancer (EORTC) Quality of Life Questionnaire-Core 30 (QLQ-C30) (version 3) and the Medical Outcomes Study 36-item Short Form Health Survey (SF-36) [10-15]. The EORTC QLQ-C30 core questionnaire contains a global health scale, five functional scales (physical, role, emotional, cognitive and social), three symptom scales (fatigue, nausea/vomiting and pain), and six single items (dyspnea, insomnia, appetite loss, constipation, diarrhea and financial difficulties). For functional scales, scores computed range from 0 to 100, with higher values representing better function. For scales evaluating symptoms and financial impact, scores range from 0 to 100 , with higher values representing a higher level of problems. The SF-36 contains eight multi-item scales: physical functioning, role-physical, role-emotional, bodily pain, social functioning, mental health, vitality and general health perceptions. Each scale is scored from 0 to 100, with higher scores representing a more favorable level of health. In addition, two summary scales - Physical Component Summary (PCS) and Mental Component Summary (MCS) - computed from the former eight scales may be studied.

Anxiety was assessed using the French version of the Spielberger State-Trait Anxiety Inventory (STAI) [16]. It contains two 20-item forms that measure state anxiety (the level of present anxiety) and trait anxiety (the general level of anxiety experienced). The global score for each form is calculated as the sum of the twelve items, with higher scores indicating more severe anxiety. Only the "state anxiety" scale was analyzed for the present study. The French version of the Multidimensional Fatigue Inventory (MFI-20) [17-19] was used to evaluate the participants' fatigue. This 20-item questionnaire is designed to measure multiple aspects of fatigue. It covers five dimensions: general fatigue, physical fatigue, reduced activity, reduced motivation and mental fatigue. Each dimension includes four items and ranges from 4 to 20 with higher scores indicating a higher degree of fatigue. A linear transformation was used to standardize raw scores giving all QOL scores ranging from 0 to 100. In addition to the above mentioned questionnaires, we collected information about family, social, professional status and comorbidity using a questionnaire for living conditions used in previous surveys [20-22]. This 
questionnaire included items on education level, marital status, children, leisure occupations, life insurance problems, employment, use of medical services and familial and social relationships. Prior to the survey, the five questionnaires were tested on 30 subjects (15 cases and 15 controls - 10 by registry area) not subsequently enrolled onto the population study.

For cases, information on clinical variables (date of diagnosis, tumor extension, surgery, radiotherapy, chemotherapy, hormone therapy, recurrence) was retrieved from medical records.

\section{Procedure}

The project was submitted to and approved by the Ethics Committee of the University Hospital of Besançon (Doubs, France) as well as by the National French Data Protection Authority (CNIL). In 2005, selected subjects were mailed a packet including (1) a letter presenting the aim of the study signed by the physician from the medical department where patients had been treated for cancer, and, for controls, by the co-investigator in charge of the study in the registry area, (2) the survey instruments, (3) an informed consent form, and (4) a postage-paid return envelope. A reminder was mailed after one month when necessary.

\section{Statistical analysis}

Descriptive analysis was performed using the Chi-square test or the Fisher's exact test for categorical variables and the Kruskal-Wallis non parametric test for the QOL scores.

In order to identify sociodemographic variables significantly linked to QOL scores, we performed a multivariate analysis of variance in controls only, separately for each QOL instrument, considering the controls as representative of the general population.

Then, we performed an analysis of variance on both cases and controls in order to compare QOL scores between cases and controls, adjusting for sociodemographic variables found significantly linked to scores in the former step. Considering the study design, the stratification variables: registry area, place of residence (urban vs. rural) and age class (four categories) were systematically introduced as explanatory variables. A four-level categorical variable was used to classify controls and cases according to time (5, 10 and 15 years) since diagnosis. Following this analysis, adjusted mean scores were computed. Two-sided tests were used in reporting the results. To account for the number of tests performed, the significance level was set at 0.01 for all tests. 
Regarding clinical significance of QOL scores, we relied on the values generally in use, following the work by Osoba et al.: a difference of 5 to 10 units (on a scale ranging from 0 to 100) was considered as small, from 10 to 20 it was considered as moderate, and a difference greater than 20 was considered as large [23].

Missing data for component items of QOL scores were treated according to published recommendations $[11,15,16]$. Statistical Analysis Software (version 9.1; SAS Institute Inc., Cary, NC) was used to analyze data [24].

\section{Power considerations}

Considering general results of QOL studies concerning the variability of scores, the present study was designed to be able to detect a difference of at least 10 points on a scale ranging from 0 to 100 when the standard deviation of the difference was equal to 60 (in a matched setting with two controls per case). With a first-type error of 0.01 and a power of ninety percent, this led to 536 cases being recruited. Consequently approximately 1,700 cases and 4,000 controls had to be selected. A thirty percent participation-rate was expected.

\section{Results}

\section{Participation-rate and participants' characteristics}

We selected 1,706 eligible breast cancer survivors. Of these, 652 completed the questionnaires, 289 for the 5 year period, 211 for the 10 year period and 152 for the 15 year period. The participation-rate was $33.7 \%$ in BasRhin, 44.2\% in Doubs and 49.8\% in Calvados. Among the 3,935 controls contacted, 1,188 completed the questionnaires. The participation rate was $23.4 \%$ in Bas-Rhin, $30 \%$ in Doubs and $33.8 \%$ in Calvados (Fig. 1). Main alleged reasons for non participation were: survey too long to complete, no time to answer or the subject was too old. Indeed, nonparticipants were older than participants (69.9 vs. 64.1 years; P $<0.0001$ for cases; 67.5 vs. 63.3 years; $\mathrm{P}<0.0001$ for controls). There were no differences between groups regarding place of residence. In the breast cancer survivors sample, nonparticipants had less chemotherapy $(22.6 \%$ vs. $30.1 \%$; $\mathrm{P}=0.0024)$ and were diagnosed more frequently during the first period than participants $(33.3 \%$ vs. $23.7 \%$; $\mathrm{P}=0.0008)$. There were no significant differences between groups with respect to tumor stage, surgery, radiotherapy or hormone therapy (this analysis was performed only on data from Doubs and Calvados).

Baseline sociodemographic characteristics of cases and controls are indicated in Table 1. There were no statistically significant differences between the two groups except for age, place of residence and monthly income. For age, a slight difference appeared in the age categories above 65 , with cases being more represented 
between 65 and 74 than controls (30.6\% vs. $24.9 \%)$. There were also more controls living in urban areas than cases $(78.4 \%$ vs. $73.0 \%)$. This distribution of the subjects was observed whatever the registry area or time since diagnosis, except for cases at 15 years who were more represented in the age category 65-74 than cases at 5 years $(40.8 \%$ vs. $25.2 \%)$.

Clinical characteristics of cases are presented in Table 2. The mean time between the diagnosis and the completion of the questionnaires was 5.6 years for cases at 5 years (standard deviation, 0.96 ), 10.3 for cases at 10 years (standard deviation, 0.60) and 15.6 for cases at 15 years (standard deviation, 0.95). As was expected, cancer survivors at 5 years were more frequently treated by chemotherapy than cancer survivors at 15 years (54.6\% vs. $39.2 \%)$. The same was true for hormone therapy. On the other hand, there were no significant differences between the three groups for surgery and radiotherapy. Particularly, the proportion of mastectomy was only moderately decreased for the more recent cases compared with the oldest cases.

\section{Controls and QOL}

According to the results of the multivariate analysis of variance, there were no statistically significant differences according to registry area or place of residence. Conversely, age class, marital status, education level, employment status, household monthly income, comorbidities and hospitalization during the last twelve months significantly influenced most of the scales. As a result, all these variables were included in the subsequent analysis of variance.

\section{Comparison of QOL between cancer survivors and controls}

\section{EORTC QLQ-C30 questionnaire}

Cancer survivors and controls showed significantly different adjusted mean scores for nearly all functional and symptom scales. Adjusted mean scores were only similar for emotional functioning, pain, constipation and diarrhea. We found a clinically significant difference, qualified as moderate, for the fatigue scale between cancer survivors at 5 years and controls (mean difference $=10.0$ ). Interestingly, we observed an improvement with time in most scales except for cognitive functioning and insomnia scales (Table 3). Fifteen years after the diagnosis, cancer survivors were no longer different from controls. Mean household monthly income influenced most of the scores, irrespective of the time since diagnosis. For instance, for social functioning and role functioning, scores raised with increasing income. Nevertheless improvement of scores with time since diagnosis was still observed for all categories of income (Fig. 2A). 


\section{SF-36 questionnaire}

All of the QOL scale scores were significantly different between cancer survivors and controls, with the exception of mental health $(\mathrm{P}=0.015)$. The most clinically significant results are shown in Table 4. Cancer survivors at 5 years showed a clinically significant difference with controls for physical functioning (mean difference $=-10.3)$, role-physical scale $($ mean difference $=-12.1)$ and role-emotional scale $($ mean difference $=$ -12.7). These differences decreased with time and 15 years after the diagnosis, cases were not longer different from controls. Physical functioning scores were higher in younger subjects, as was expected, but scores still increased with time since diagnosis for each age category. The same was true for role-emotional scores (Fig. 2B).

\section{MFI-20 and Spielberger questionnaires}

Cancer survivors had higher adjusted mean scores, indicating more fatigue, in all dimensions of the MFI-20 scale compared with the controls. The highest score was observed for general fatigue (49.8). Although all the differences between cases and controls were statistically significant, clinically significant differences were only found at 5 years for the general fatigue scale (mean difference $=11.3$ ) and the physical fatigue scale (mean difference $=12.0$ ). The adjusted mean scores decreased across time, leading to clinically non significant differences 15 years after the diagnosis, except for the mental fatigue scale (mean difference $=5.9$ ). Reduced activity scores increased with age, as was expected, but decreased with time in every age category. Furthermore, physical fatigue scores decreased with increasing income, but the effect of time since diagnosis was not noticeable for the lowest income category (Fig. 3).

For the STAI scale, cancer survivors had higher adjusted mean scores (34.4 for cases at 5 years, 34.7 for cases at 10 years, 33.2 for cases at 15 years), indicating more anxiety, compared with controls $(28.5)(\mathrm{P}<0.0001)$.

\section{Discussion}

This study demonstrates that long-term QOL, in general, and more specifically components of QOL such as fatigue, physical functioning and role limitations due to physical problems or emotional problems, are impaired by the occurrence of breast cancer in women. However, the gap between breast cancer survivors and populationbased controls seems to narrow as the time since onset of the disease increases. Indeed, cancer survivors at five years reported significantly poorer QOL scores compared to controls. However, differences decreased with time: 
cancer survivors at fifteen years showed higher QOL scores than patients with shorter time since diagnosis and were no longer different from controls.

In comparison with other population-based QOL studies, controls of the present study showed similar scores. For instance, the crude SF-36 mean scores of controls, by age category, were comparable to reference values of the general French population [15]. As no reference values for the QLQ-C30 scores were available in the French general population, we compared these scores with results from a German population-based study [25]. The crude QLQ-C30 mean scores were similar to the reference values of the general German population except for cognitive functioning, fatigue, pain, dyspnea, insomnia and constipation: for these scales, the French women in our study had higher scores. Finally, the crude MFI-20 mean scores were similar to the reference values of the Danish general population, except for mental fatigue and reduced motivation for which the healthy controls showed higher scores [26]. Consequently, we considered that our sample of controls was suited for comparison with the cases.

Results for cases were difficult to compare with information from other population-based studies. Indeed, most of detailed published results for QOL scores are adjusted on many variables, including age and several other factors such as education level or marital status. We could not find published adjusted results for the same covariables as ours. However, when compared with results of a United States cross-sectional study, crude SF-36 scores were lower in our study, even though mean time since diagnosis was only 3 years in the mentioned study $[5]$.

The findings of better physical functioning in the 15 year group in comparison with the 5 year group could in part be explained by a response shift. Survivors remaining disease-free for up to 15 years since initial diagnosis could have adopted a more pragmatic attitude regarding their everyday life experience, resulting in an improvement of perceived QOL. This result is in accordance with data of a study comparing QOL during disease progression with QOL for disease-free survivors up to 15 years after initial diagnosis and with QOL of a normative population [27].

The study design did not allow to disentangle effects of time since diagnosis from period effects, as time since diagnosis was different between the three groups. Such effects would tend to reduce the estimated difference in QOL between five-, ten- and fifteen-year survivors. Indeed, progress in breast cancer therapy, with a greater proportion of recent cases undergoing breast-conservative therapy or treated with improved chemotherapy, results in reduced side-effects and more favorable outcomes. However, in our study, there were only slight differences in the proportion of lumpectomies between five- and fifteen-year survivors (66.7\% vs $62.2 \%)$. 
Complementary analyses are in progress to explore in greater details the impact of disease severity and of treatment characteristics on QOL five-, ten- and fifteen-years after diagnosis.

Consequently, we may conclude that, in the absence of such effects, even greater differences would have been observed between five-year survivors and fifteen-year survivors.

The environmental and socioeconomic setting being different between the three areas, regional differences in QOL from one registry area to another were expected. Results demonstrated that no such differences existed, at least for the three French geographical areas considered. Place of residence (urban vs. rural) did not influence QOL either.

On the other hand, sociodemographic characteristics such as age, education level and household monthly income were associated with QOL, both for cases and controls. These findings support results of earlier research [28]. In addition to the use of validated standardized QOL questionnaires, the strength of the present study relies on the number of cases and controls included, on the population-based selection of cases and controls and on the three time-periods after diagnosis considered. A limitation of the study is its cross-sectional design, which did not allow to take into account individual changes in QOL over time.

Participation-rate was similar to rates reported for other population-based studies with mailed questionnaires [29]. As usually observed, participation for cases was slightly higher than for controls. Participants were slightly younger than nonparticipants for cases as well for controls. In the breast cancer survivors sample, there were no major differences in treatment-related variables between nonparticipants and participants. Thus, selection bias was limited. The variation in response rates across the three registries may be explained by the fact that NorthWestern inhabitants were more often approached to participate in mail surveys than Eastern inhabitants.

In conclusion, on the basis of these results, more efforts should be made, specifically during the first five to ten years after diagnosis, to help women with breast cancer to overcome the impairment in QOL evidenced on many scales.

\section{Acknowledgments}

This research is supported by grants from the French hospital research programme (Programme Hospitalier de Recherche Clinique), the "Fondation de France", the "Ligue Contre le Cancer du Doubs" and the "Institut National du Cancer". The authors wish to thank all the physicians from the three cancer registries areas who kindly agreed to ask cases they had treated to participate in the study. 


\section{References}

1. Belot A, Grosclaude P, Bossard N et al (2008) Cancer incidence and mortality in France over the period 1980-2005. Rev Epidemiol Sante Publique 56(3):159-175

2. Curado MP, Edwards B, Shin HR, Storm H, Ferlay J, Heanue M, Boyle P (2007) Cancer incidence in five continents Vol. IX. IARC, Lyon

3. Robb C, Haley WE, Balducci L, Extermann M, Perkins EA, Small BJ, Mortimer J (2007) Impact of breast cancer survivorship on quality of life in older women. Crit Rev Oncol Hematol 62(1):84-91

4. Sweeney C, Schmitz KH, Lazovich D, Virnig BA, Wallace RB, Folsom AR (2006) Functional limitations in elderly female cancer survivors. J Natl Cancer Inst 98(8):521-529

5. Ganz PA, Rowland JH, Desmond K, Meyerowitz BE, Wyatt GE (1998) Life after breast cancer: understanding women's health-related quality of life and sexual functioning. J Clin Oncol 16(2):501-514

6. Ganz PA, Desmond KA, Leedham B, Rowland JH, Meyerowitz BE, Belin TR (2002) Quality of life in long-term, disease-free survivors of breast cancer: a follow-up study. J Natl Cancer Inst 94(1):39-49

7. Baker F, Haffer SC, Denniston M (2003) Health-related quality of life of cancer and noncancer patients in Medicare managed care. Cancer 97(3):674-681

8. Michael YL, Kawachi I, Berkman LF, Holmes MD, Colditz GA (2000) The persistent impact of breast carcinoma on functional health status: prospective evidence from the Nurses' Health Study. Cancer 89(11):2176-2186

9. Peuckmann V, Ekholm O, Rasmussen NK, Møller S, Groenvold M, Christiansen P, Eriksen J, Sjøgren P (2007) Heath-related quality of life in long-term breast cancer survivors: nationwide survey in Denmark. Breast Cancer Res Treat 104(1):39-46

10. Aaronson NK, Ahmedzai S, Bergman B et al (1993) The European Organization for Research and Treatment of Cancer QLQ-C30: a quality-of-life instrument for use in international clinical trials in oncology. J Natl Cancer Inst 85(5):365-376

11. Fayers PM, Aaronson NK, Bjordal K, Groenvold M, Curran D, Bottomley A (2001) EORTC QLQ-C30 Scoring Manual, 3rd edn. EORTC, Brussels

12. McHorney CA, Ware JE Jr, Raczek AE (1993) The MOS 36-item Short-Form Health Survey (SF-36): II. Psychometric and clinical tests of validity in measuring physical and mental health constructs. Med Care $31(3): 247-263$ 
13. McHorney CA, Ware JE Jr, Lu JF, Sherbourne CD (1994) The MOS 36-item Short-Form Health Survey (SF-36): III. Tests of data quality, scaling assumptions and reliability across diverse patients groups. Med Care 32(1):40-66

14. Leplège A, Mesbah M, Marquis P (1995) Preliminary analysis of the psychometric properties of the French version of an international questionnaire measuring the quality of life: the MOS SF-36 (version 1.1). Rev Epidemiol Sante Publique 43(4):371-379

15. Leplège A, Ecosse E, Pouchot J, Coste J, Perneger T (2001) Le questionnaire MOS SF-36. Manuel de l'utilisateur et guide d'interprétation des scores. ESTEM, Paris

16. Spielberger CD (1993) Manuel inventaire d'anxiété état-trait: adaptation française de Bruchon-Schweitzer M, Paulhan I. Les éditions du centre de psychologie appliquée, Paris

17. Smets EM, Garssen B, Bonke B, De Haes JC (1995) The Multidimensional Fatigue Inventory (MFI) psychometric qualities of an instrument to assess fatigue. J Psychosom Res 39(3):315-325

18. Gentile S, Delarozière JC, Favre F, Sambuc R, San Marco JL (2003) Validation of the French 'multidimensional fatigue inventory' (MFI-20). Eur J Cancer Care 12(1):58-64

19. Smets EM, Garssen B, Cull A, de Haes JC (1996) Application of the multidimensional fatigue inventory (MFI-20) in cancer patients receiving radiotherapy. Br J Cancer 73(2):241-245

20. Joly F, Henry-Amar M, Arveux P, Reman O, Tanguy A, Peny AM, Lebailly P, Macé-Lesec'h J, Vié B, Génot JY, Busson A, Troussard X, Leporrier M (1996) Late psychosocial sequelae in Hodgkin's disease survivors: a French population-based case-control study. J Clin Oncol 14(9):2444-2453

21. Joly F, Espié M, Marty M, Héron JF, Henry-Amar M (2000) Long-term quality of life in premenopausal women with node-negative localized breast cancer treated with or without adjuvant chemotherapy. Br $\mathrm{J}$ Cancer 83(5):577-582

22. Joly F, Héron JF, Kalusinski L, Bottet P, Brune D, Allouache N, Macé-Lesec'h J, Couëtte JE, Pény J, Henry-Amar M (2002) Quality of life in long-term survivors of testicular cancer: a population-based casecontrol study. J Clin Oncol 20(1):73-80

23. Osoba D, Rodrigues G, Myles J, Zee B, Pater J (1998) Interpreting the significance of changes in healthrelated quality-of-life scores. J Clin Oncol 16(1):139-144

24. SAS Institute Inc (1996) SAS/STAT User's Guide. Vol. 1. Cary, NC, SAS Institute Inc

25. Schwarz R, Hinz A (2001) Reference data for the quality of life questionnaire EORTC QLQ-C30 in the general German population. Eur J Cancer 37(11):1345-1351 
26. Watt T, Groenvold M, Bjorner JB, Noerholm V, Rasmussen NA, Bech P (2000) Fatigue in the Danish general population. Influence of sociodemographic factors and disease. J Epidemiol Community Health 54(11):827-833

27. Thong MS, Mols F, Coebergh JW, Roukema JA, van de Poll-Franse LV (2009) The impact of disease progression on perceived health status and quality of life of long-term cancer survivors. J Cancer Surviv $3(3): 164-173$

28. Cui Y, Shu XO, Gao Y, Cai H, Wen W, Ruan ZX, Jin F, Zheng W (2004) The long-term impact of medical and socio-demographic factors on the quality of life of breast cancer survivors among Chinese women. Breast Cancer Res Treat 87(2):135-147

29. Hager MA, Wilson S, Pollak TH, Rooney PM (2003) Response rates for mail surveys of nonprofit organizations: a review and empirical test. Nonprofit Voluntary Sector Q 32:252-267

\section{Figure legends}


Fig. 1 Study design

Fig. 2 Quality of life crude mean scores according to sociodemographic characteristics. Higher scores indicate a better health status. (a) EORTC QLQ-C30, European Organization for Research and Treatment of Cancer Quality of Life Questionnaire Core 30. Functional scales according to monthly income. (b) SF-36, Medical Outcomes Study 36-item Short Form. Scales according to age

Fig. 3 Multidimensional Fatigue Inventory (MFI-20) crude mean scores according to sociodemographic characteristics. Higher scores indicate a higher degree of fatigue 


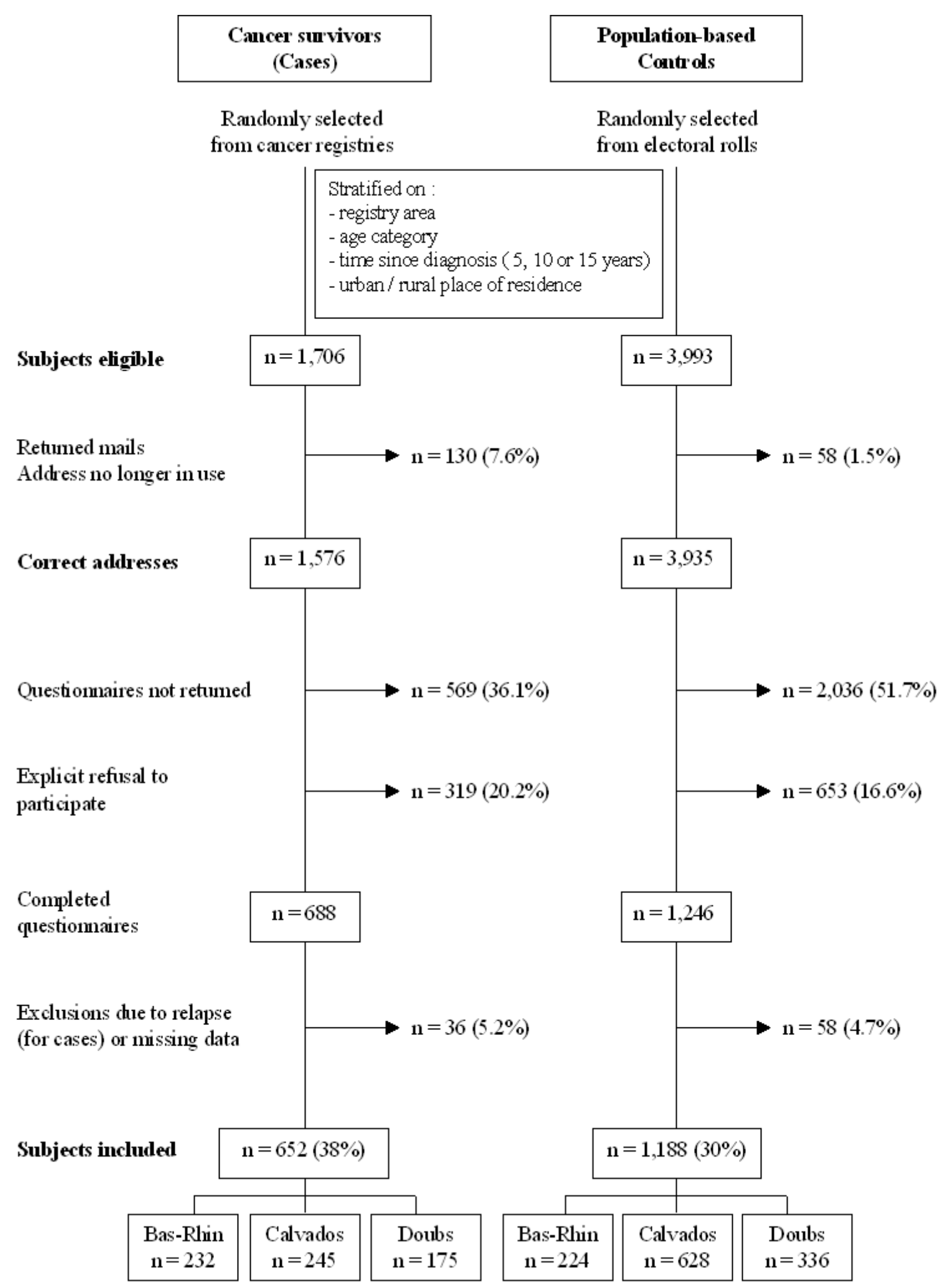


a

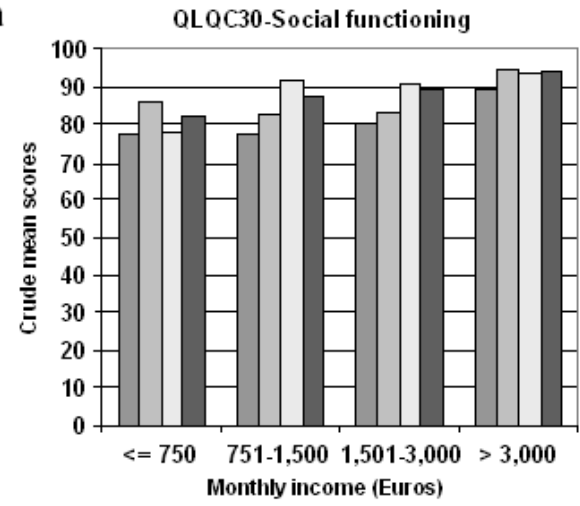

b

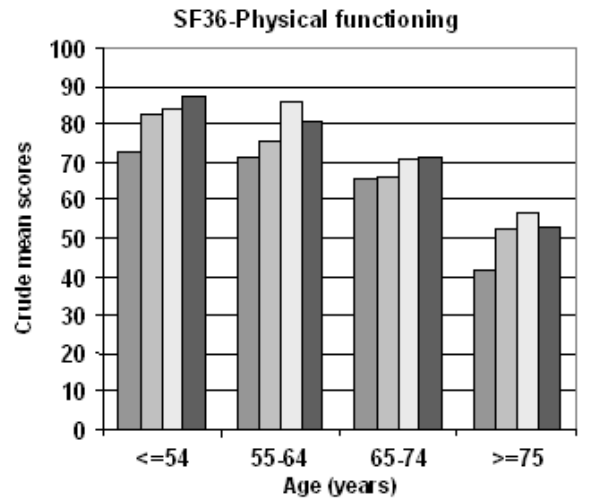

$\square$ Cases 15 years $\square$ Controls
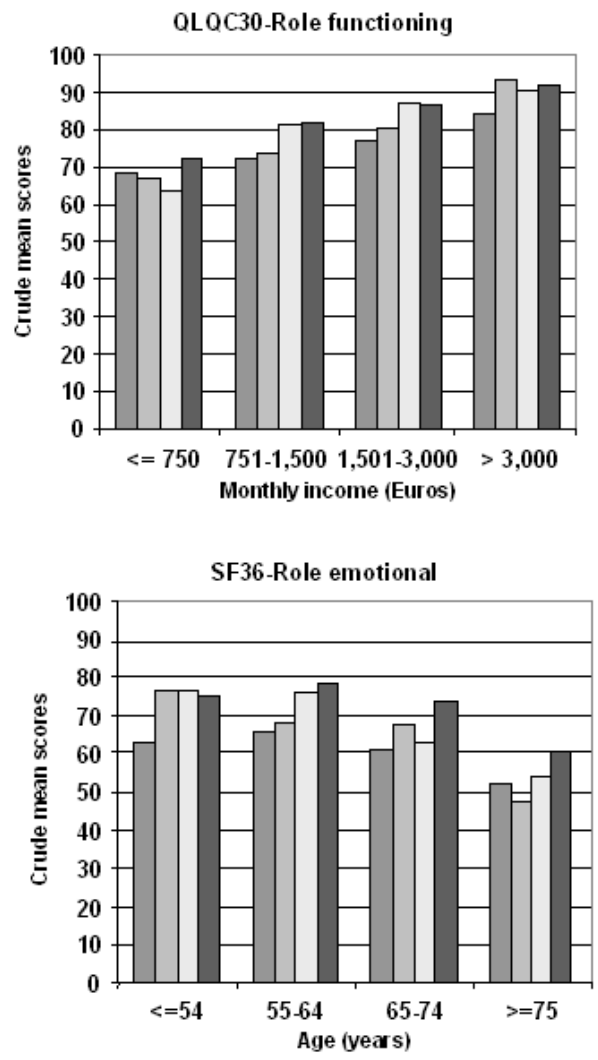

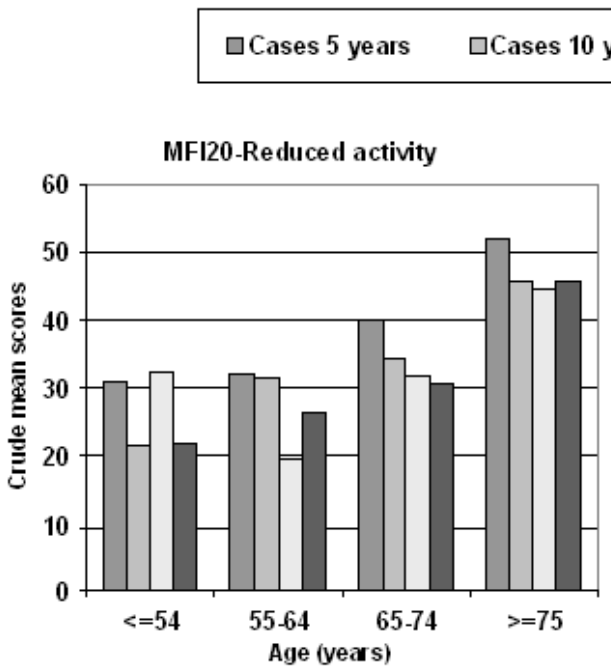

$\square$ Cases 15 years $\square$ Controls

Table 1 Sociodemographic characteristics at baseline

\begin{tabular}{lccc}
\hline Characteristics & \multicolumn{2}{c}{ No. (\%) } & Controls \\
& $(\mathrm{n}=652)$ & P value* \\
Age at interview (years) & & & 0.007 \\
\hline
\end{tabular}




\begin{tabular}{|c|c|c|c|}
\hline$\leq 54$ & $127(19.5)$ & $268(22.6)$ & \\
\hline $55-64$ & $219(33.6)$ & $377(31.7)$ & \\
\hline $65-74$ & $200(30.6)$ & $296(24.9)$ & \\
\hline$\geq 75$ & $106(16.3)$ & $247(20.8)$ & \\
\hline Place of residence & & & 0.008 \\
\hline Rural & $176(27.0)$ & $256(21.6)$ & \\
\hline Urban & $476(73.0)$ & $932(78.4)$ & \\
\hline Education level & & & 0.06 \\
\hline Low & $331(50.8)$ & $570(48.0)$ & \\
\hline Middle & $222(34.1)$ & $392(33.0)$ & \\
\hline High & $87(13.3)$ & $212(17.8)$ & \\
\hline Unknown & $12(1.8)$ & $14(1.2)$ & \\
\hline Marital status & & & 0.64 \\
\hline Single & $42(6.5)$ & $69(5.8)$ & \\
\hline Married/living with partner & $441(67.6)$ & $779(65.6)$ & \\
\hline Separated/divorced/widowed & $165(25.3)$ & $332(27.9)$ & \\
\hline Unknown & $4(0.6)$ & $8(0.7)$ & \\
\hline Number of children & & & 0.17 \\
\hline 0 & $74(11.3)$ & $128(10.8)$ & \\
\hline 1 & $119(18.2)$ & $199(16.7)$ & \\
\hline 2 & $226(34.7)$ & $392(33.0)$ & \\
\hline$\geq 3$ & $224(34.4)$ & $462(38.9)$ & \\
\hline Unknown & $9(1.4)$ & $7(0.6)$ & \\
\hline Employment status & & & 0.30 \\
\hline Unemployed/housewife/retired & $473(72.5)$ & $822(69.2)$ & \\
\hline Employed & $176(27.0)$ & $361(30.4)$ & \\
\hline Unknown & $3(0.5)$ & $5(0.4)$ & \\
\hline Monthly income (Euros) & & & 0.01 \\
\hline$\leq 750 \quad(\$ 1,011)$ & $78(12.0)$ & $146(12.3)$ & \\
\hline $751-1,500 \quad(\$ 1,012-\$ 2,022)$ & $178(27.3)$ & $318(26.8)$ & \\
\hline $1,501-3,000(\$ 2,023-\$ 4,043)$ & $203(31.1)$ & $390(32.8)$ & \\
\hline$>3,000 \quad(\$ 4,043)$ & $118(18.1)$ & $250(21.0)$ & \\
\hline Unknown & $75(11.5)$ & $84(7.1)$ & \\
\hline Comorbidities & & & 0.08 \\
\hline 0 & $99(15.2)$ & $138(11.6)$ & \\
\hline 1 & $196(30.1)$ & $348(29.3)$ & \\
\hline 2 & $165(25.3)$ & $320(26.9)$ & \\
\hline$\geq 3$ & $164(25.1)$ & $344(29.0)$ & \\
\hline Unknown & $28(4.3)$ & $38(3.2)$ & \\
\hline
\end{tabular}

Table 2 Clinical characteristics of breast cancer survivors ${ }^{a}$

\begin{tabular}{|c|c|c|c|c|}
\hline Characteristics & $\begin{array}{c}\text { Cancer survivors } \\
5 \text { years } \\
(\mathrm{n}=282)\end{array}$ & $\begin{array}{c}\text { No. }(\%) \\
\text { Cancer survivors } \\
10 \text { years } \\
(\mathrm{n}=210) \\
\end{array}$ & $\begin{array}{c}\text { Cancer survivors } \\
15 \text { years } \\
(\mathrm{n}=143) \\
\end{array}$ & $P$ value \\
\hline pT classification & & & & $0.0003^{*}$ \\
\hline $\mathrm{T} 0-\mathrm{T} 1^{\mathrm{b}}$ & $162(57.5)$ & $110(52.4)$ & $62(43.3)$ & \\
\hline $\mathrm{T} 2$ & $63(22.3)$ & $58(27.6)$ & $28(19.6)$ & \\
\hline T3-T4 & $15(5.3)$ & $5(2.4)$ & $6(4.2)$ & \\
\hline $\mathrm{TX}$ & $42(14.9)$ & $37(17.6)$ & $47(32.9)$ & \\
\hline Surgery & & & & $0.71^{*}$ \\
\hline No surgery & $2(0.7)$ & $1(0.5)$ & $0(0.0)$ & \\
\hline Lumpectomy & $188(66.7)$ & $134(63.8)$ & $89(62.2)$ & \\
\hline Mastectomy & $92(32.6)$ & $74(35.2)$ & $54(37.8)$ & \\
\hline
\end{tabular}




\begin{tabular}{|c|c|c|c|c|}
\hline Radiotherapy & & & & $0.71^{* * *}$ \\
\hline Yes & $235(83.3)$ & $172(81.9)$ & $120(83.9)$ & \\
\hline No & $45(16.0)$ & $35(16.7)$ & $20(14.0)$ & \\
\hline Unknown & $2(0.7)$ & $3(1.4)$ & $3(2.1)$ & \\
\hline Chemotherapy & & & & $0.0008^{* *}$ \\
\hline Yes & $154(54.6)$ & $81(38.6)$ & $56(39.2)$ & \\
\hline No & $127(45.0)$ & $126(60.0)$ & $85(59.4)$ & \\
\hline Unknown & $1(0.4)$ & $3(1.4)$ & $2(1.4)$ & \\
\hline Hormone therapy & & & & $<0.0001^{* *}$ \\
\hline Yes & $236(83.7)$ & $129(61.4)$ & $67(46.9)$ & \\
\hline No & $43(15.2)$ & 79 (37.6) & $71(49.6)$ & \\
\hline Unknown & $3(1.1)$ & $2(1.0)$ & $5(3.5)$ & \\
\hline \multicolumn{5}{|c|}{${ }^{a}$ Seventeen cases excluded due to missing information on treatment characteristics } \\
\hline \multicolumn{5}{|l|}{${ }^{\mathrm{b}}$ Only 7 pT0 cases } \\
\hline \multicolumn{5}{|l|}{ * Chi-square test } \\
\hline
\end{tabular}

Table 3 EORTC QLQ-C30 scores by group ${ }^{\mathrm{a}}$

\begin{tabular}{|c|c|c|c|c|c|}
\hline \multirow[b]{2}{*}{ Quality-of-Life Measure } & \multirow[b]{2}{*}{ Group } & \multicolumn{2}{|c|}{ Crude } & \multicolumn{2}{|c|}{ Adjusted $^{b}$} \\
\hline & & Mean & $\mathrm{SD}$ & Mean difference $^{\mathrm{c}}$ & $\mathrm{P}$ value \\
\hline \multicolumn{6}{|c|}{ Functional scales (higher scores indicate better functioning) } \\
\hline \multirow[t]{4}{*}{ Physical functioning } & Controls & 84.6 & 19.0 & & $<0.0001$ \\
\hline & Cases 5 years & 80.9 & 17.8 & -6.0 & \\
\hline & Cases 10 years & 82.4 & 18.0 & -3.0 & \\
\hline & Cases 15 years & 83.7 & 18.0 & -0.6 & \\
\hline \multirow[t]{4}{*}{ Role functioning } & Controls & 84.5 & 25.6 & & $<0.0001$ \\
\hline & Cases 5 years & 76.4 & 27.2 & -9.2 & \\
\hline & Cases 10 years & 79.0 & 26.2 & -4.2 & \\
\hline & Cases 15 years & 81.9 & 28.1 & -1.1 & \\
\hline \multirow[t]{4}{*}{ Social functioning } & Controls & 88.6 & 23.9 & & $<0.0001$ \\
\hline & Cases 5 years & 80.8 & 27.3 & -7.8 & \\
\hline & Cases 10 years & 85.7 & 24.1 & -2.8 & \\
\hline & Cases 15 years & 89.3 & 18.1 & 0.7 & \\
\hline \multirow[t]{4}{*}{ Global health status } & Controls & 69.2 & 20.5 & & 0.0035 \\
\hline & Cases 5 years & 65.1 & 19.4 & -4.6 & \\
\hline & Cases 10 years & 65.4 & 21.2 & -2.9 & \\
\hline & Cases 15 years & 67.6 & 20.2 & -1.4 & \\
\hline
\end{tabular}

Symptom scales (higher scores indicate a higher level of problems) 
Fatigue

$$
\text { Controls }
$$

$24.4 \quad 23.8$

$<0.0001$

Cases 5 years

$33.6 \quad 26.0$

10.0

Cases 10 years

$30.5 \quad 25.4$

6.0

Cases 15 years

$25.8 \quad 23.6$

1.5

Dyspnea

Controls

Cases 5 years

Cases 10 years

Cases 15 years
$15.7 \quad 24.2$

$22.5 \quad 27.8$

8.5

$23.1 \quad 29.3$

$19.6 \quad 26.7$
7.0

$<0.0001$

2.9

EORTC QLQ-C30 = European Organization for Research and Treatment of Cancer Quality of Life

Questionnaire Core 30

$\mathrm{SD}=$ standard deviation

${ }^{a}$ Scores range from 0 to 100

${ }^{\mathrm{b}}$ Adjusted for registry area, age, place of residence (urban/rural), marital status, education level, employment status, mean household monthly income, comorbidities and hospitalization during the last twelve months (Analysis of variance)

${ }^{\mathrm{c}}$ Computed as Adjusted mean(Cases) - Adjusted mean(Controls)

Table 4 SF-36 scores by group - Higher scores indicate a better health status ${ }^{\mathrm{a}}$

\begin{tabular}{|c|c|c|c|c|c|}
\hline \multirow[b]{2}{*}{ Quality-of-Life Measure } & \multirow[b]{2}{*}{ Group } & \multicolumn{2}{|c|}{ Crude } & \multicolumn{2}{|c|}{ Adjusted $^{\mathrm{b}}$} \\
\hline & & Mean & $\mathrm{SD}$ & Mean difference ${ }^{c}$ & $\mathrm{P}$ value \\
\hline \multirow[t]{4}{*}{ Physical functioning } & Controls & 74.3 & 26.5 & & $<0.0001$ \\
\hline & Cases 5 years & 67.1 & 24.6 & -10.3 & \\
\hline & Cases 10 years & 69.6 & 23.8 & -4.6 & \\
\hline & Cases 15 years & 74.3 & 23.6 & -0.1 & \\
\hline \multirow[t]{4}{*}{ Role-physical } & Controls & 70.1 & 38.0 & & $<0.0001$ \\
\hline & Cases 5 years & 60.4 & 38.7 & -12.1 & \\
\hline & Cases 10 years & 63.1 & 39.4 & -8.0 & \\
\hline & Cases 15 years & 70.9 & 38.6 & -0.6 & \\
\hline \multirow[t]{4}{*}{ Role-emotional } & Controls & 72.8 & 37.9 & & $<0.0001$ \\
\hline & Cases 5 years & 62.3 & 40.7 & -12.7 & \\
\hline & Cases 10 years & 65.5 & 39.8 & -9.5 & \\
\hline & Cases 15 years & 66.7 & 40.6 & -8.1 & \\
\hline
\end{tabular}


General health perceptions

$\begin{array}{llll}\text { Controls } & 64.9 & 20.3 & \\ \text { Cases 5 years } & 58.7 & 21.9 & -7.7 \\ \text { Cases 10 years } & 60.6 & 21.7 & -5.0 \\ \text { Cases 15 years } & 64.0 & 21.8 & -0.6\end{array}$

Summary scales

Physical Component

\section{Controls}

Cases 5 years

Cases 10 years

Cases 15 years

Mental Component

\section{Controls}

Cases 5 years

Cases 10 years

Cases 15 years
46.5

9.7

43.8

44.2

46.8

47.1

10.8

$43.9 \quad 11.6$

$-2.7$

$46.1 \quad 10.7$

$-1.8$

45.9

11.4

$-1.8$

SF-36 = Medical Outcomes Study 36-item short form

$\mathrm{SD}=$ standard deviation

${ }^{a}$ Scores range from 0 to 100

${ }^{\mathrm{b}}$ Adjusted for registry area, age, place of residence (urban/rural), marital status, education level, employment status, mean household monthly income, comorbidities and hospitalization during the last twelve months (Analysis of variance)

${ }^{\mathrm{c}}$ Computed as Adjusted mean(Cases) - Adjusted mean(Controls) 